\title{
低温制备不锈钢表面含铜磷酸铝涂层及抗菌性能研究
}

\author{
王东微，董英豪，周 杰，段可，鲁 雄，汪建新，冯 波，屈树新，翁 杰 \\ (西南交通大学 材料科学与工程学院, 材料先进技术教育部重点实验室, 成都 610031)
}

摘 要: 利用磷酸二氢铝的固化反应在 316 不锈钢表面制备了不同含量 $\mathrm{Cu}^{2+}$ 的磷酸铝涂层 $(\mathrm{Cu}: \mathrm{Al}=0.025 、 0.05 、 0.1)$ 。 差示扫描量热分析及 $X$ 射线衍射表明涂层材料可在 $\leqslant 250^{\circ} \mathrm{C}$ 下固化, 主要固化产物为 $\mathrm{AlH}_{2} \mathrm{P}_{3} \mathrm{O}_{10} \cdot 2 \mathrm{H}_{2} \mathrm{O} 、 \mathrm{AlPO}_{4}$ 和 $\mathrm{Al}_{8} \mathrm{H}_{12}\left(\mathrm{P}_{2} \mathrm{O}_{7}\right)_{9}$ 。 $\mathrm{Cu}^{2+}$ 加入后产生了含铜的新相 $\mathrm{Cu}_{2} \mathrm{P}_{2} \mathrm{O}_{7}$ 。与大肠杆菌共培养 $12 \mathrm{~h}$ 后各含 $\mathrm{Cu}^{2+}$ 涂层表现出抗菌性, 且 抗菌能力与 $\mathrm{Cu}^{2+}$ 含量正相关; 接触 $24 \mathrm{~h}$ 后, 所有含 $\mathrm{Cu}^{2+}$ 涂层表面均无活菌检出。菌悬液中加入 EDTA 有效抑制了 涂层抗菌活性，表明涂层抗菌性能来自表面溶出的 $\mathrm{Cu}^{2+}$ 。拉伸试验表明涂层结合强度在 14.5 18.1 MPa 范围。与无 涂层的不锈钢相比, 涂覆涂层后样品的腐蚀电流密度下降了 2 个数量级。

关 键 词: 铜; 磷酸铝; 涂层; 抗菌

中图分类号: TQ174 文献标识码: A

\section{Low-temperature Preparation of Cu-containing Aluminum Phosphate Coatings on Stainless Steel and Antibacterial Properties}

\author{
WANG Dong-Wei, DONG Ying-Hao, ZHOU Jie, DUAN Ke, LU Xiong, \\ WANG Jian-Xin, FENG Bo, QU Shu-Xin, WENG Jie
}

(Key Laboratory of Advanced Technologies of Materials, Ministry of Education, School of Materials Science and Engineering, Southwest Jiaotong University, Chengdu 610031, China)

\begin{abstract}
Aluminum phosphate coatings containing different levels of $\mathrm{Cu}^{2+}$ ions $(\mathrm{Cu} / \mathrm{Al}$ molar ratio: 0.025, 0.05, 0.1 ) were prepared on 316-stainless steel based on the curing reaction of monoaluminium phosphate (MAP). The curing behaviors of the starting materials and phase compositions of the cured products were studied by differential scanning calorimetry and $\mathrm{X}$-ray diffraction, respectively. Results indicate that the copper-free MAP cures at $\leqslant 250^{\circ} \mathrm{C}$ to form 3 major phases: $\mathrm{AlH}_{2} \mathrm{P}_{3} \mathrm{O}_{10} \cdot 2 \mathrm{H}_{2} \mathrm{O}$, $\mathrm{AlPO}_{4}$, and $\mathrm{Al}_{8} \mathrm{H}_{12}\left(\mathrm{P}_{2} \mathrm{O}_{7}\right)_{9}$. When $\mathrm{Cu}^{2+}$ ions are introduced into the MAP, an additional phase of $\mathrm{Cu}_{2} \mathrm{P}_{2} \mathrm{O}_{7}$ appears in the cured product. E. coli was inoculated on the surfaces of coatings to evaluate their antibacterial properties. After co-culture with $E$. Coli for $12 \mathrm{~h}$, all $\mathrm{Cu}^{2+}$-containing coatings exhibit antibacterial effect and show a positive association between $\mathrm{Cu}^{2+}$ content and antibacterial activity. After co-culture for $24 \mathrm{~h}$, no viable bacteria remain on any $\mathrm{Cu}^{2+}$-containing coating. The addition of ethylenediaminetetraacetic acid to the culture medium substantially inhibits the antibacterial activities of all coatings, confirming that the antibacterial effect is attributed to the release of $\mathrm{Cu}^{2+}$ ions from coatings. Pull-out tests show that the bonding strengths of the coatings range between 14.5-18.1 MPa. Potentiodyanmic polarization indicates that the coatings reduce the corrosion current density of the stainless steel substrate by approximately two orders of magnitude.
\end{abstract}

收稿日期: 2016-06-17; 收到修改稿日期：2016-10-09

基金项目：国家自然科学基金（51372210，51572228); 教育部博士点基金(20130184110023); 四川省应用基础研究计划 (2016JY0011)

National Natural Science Foundation of China (51372210, 51572228); Ph.D Program Foundation of MOE (20130184110023); Basic Applied Research Program of Sichuan Province (2016JY0011)

作者简介: 王东微(1985-), 女，博士研究生. E-mail: wdw_swjtu@163.com

通讯作者: 段 可, 副教授. E-mail: keduan@home.swjtu.edu.cn 
Key words: copper; aluminum phosphate; coating; antibacterial

不锈钢具有良好的耐腐蚀性和机械性能，广泛 用于各种设施，如公交车辆的栏杆、扶手等。使用 中，这些设施表面可通过大气或人体接触等途径被 细菌污染而成为二次传染源 ${ }^{[1]}$ 。赋予不锈钢抗菌性 可抑制这一传播途径。铜、银等元素对多种细菌具 有杀灭能力，可应用于制备各种抗菌复合材料 ${ }^{[2-5]}$ 。其 中铜由于价格相对较低而被用于制备抗菌合金。Nan 等 ${ }^{[6]}$ 制备了含铜的抗菌不锈钢，该材料通过表层的 含铜相溶出 $\mathrm{Cu}^{2+}$ 杀灭细菌, 但其体相中的铜不参与 抗菌, 因此铜的利用率较低。此外, 铜元素还会导致 不锈钢的耐腐蚀性和力学性能劣化 ${ }^{[7]}$ 。因此, 通过表 面改性技术制备表面含铜的涂层可望更有效地利用 铜的抗菌性能而不降低不锈钢的耐腐蚀性。有研究采 用离子注入等方法制备了表面含铜的抗菌不锈钢 ${ }^{[7-8]}$, 但实验过程中需要真空, 不易应用于大尺寸部件和 批量制造。Trapalis 等 ${ }^{[9]}$ 采用溶胶-凝胶法在玻璃表面 制备了含铜二氧化硅涂层, 并证实涂层可杀灭大肠 杆菌。溶胶-凝胶法可应用于不锈钢 ${ }^{[10]}$, 但其高温烧 结 $\left(500^{\circ} \mathrm{C}\right)$ 过程 ${ }^{[9]}$ 耗能且可导致不锈钢发生热敏化 ${ }^{[11]}$ 而影响其耐腐蚀性。

磷酸铝是一种低温固化的无机聚合物 ${ }^{[12]}$, 其涂 层可用于防护金属腐蚀和磨损 ${ }^{[13-14]}$ 。磷酸铝结构中 可掺入与 $\mathrm{Al}^{3+}$ 半径相近的离子, 如 $\mathrm{Zn}^{2+} 、 \mathrm{Cu}^{2+}$ 等 ${ }^{[15]}$, 但目前尚无研究利用磷酸铝基体掺杂抗菌元素在金 属表面制备抗菌涂层。利用无机聚合物为基体制备 抗菌涂层，可望具有制备温度较低、不影响基底金 属性能和适用于批量制造等优点。本工作采用溶胶凝胶法在不锈钢表面制备掺 $\mathrm{Cu}^{2+}$ 的磷酸铝涂层, 并 研究了涂层形成机理、材料结构、抗菌性能和耐腐 蚀性。

\section{1 实验方法}

\section{1 材料制备}

除另有说明，所用试剂均为分析纯，购自成都 科龙化工试剂厂。316 不锈钢样品(316-SS, $\phi 22 \mathrm{~mm} \times$ $1.5 \mathrm{~mm}$ ，成都华睿金属材料有限公司)丙酮清洗后 $\mathrm{Al}_{2} \mathrm{O}_{3}$ 喷砂粗化。100 $\mathrm{g}$ 磷酸(85\%)溶于 $100 \mathrm{~mL}$ 蒸馏 水, $80^{\circ} \mathrm{C}$ 下加入 $29.4 \mathrm{~g} \mathrm{Al}(\mathrm{OH})_{3}$ 并搅拌溶解。所得溶 液分为 4 份, 其中 3 份加入适量 $\mathrm{Cu}(\mathrm{OH})_{2}$ 并摚拌溶 解, 使溶液中 $\mathrm{Cu}: \mathrm{Al}$ 摩尔比分别为 1:40、1:20 和 $1: 10$ 。所得 4 种涂层溶液分别记为 $\operatorname{AlP}($ 无铜磷酸二
氢铝)、AlP- $0.025 \mathrm{Cu} 、 \mathrm{AlP}-0.05 \mathrm{Cu}$ 和 AlP- $-0.1 \mathrm{Cu}$ 。

为了避免 $\mathrm{Cu}^{2+}$ 接触 316-SS 表面还原为 $\mathrm{Cu}(0)$, 先将适量 $\mathrm{AlP}$ 溶液均匀涂刷于样品表面, 烘干 $\left(80^{\circ} \mathrm{C}\right.$, $2 \mathrm{~h}$ )后 $250^{\circ} \mathrm{C}$ 固化 $2 \mathrm{~h}$, 形成一层无铜磷酸铝涂层。 再用上述各涂层溶液分别涂刷样品表面, $250^{\circ} \mathrm{C}$ 固化 $2 \mathrm{~h}$ 。根据表面(第 2 层)涂层的铜含量, 样品分别记 为 316-AlP、316-AlP-0.025Cu、316-AlP-0.05Cu 和 316-AlP-0.1Cu。此外, 将各涂层溶液烘干 $\left(80^{\circ} \mathrm{C}, 24 \mathrm{~h}\right)$ 后研磨成粉体用于表征固化性能和产物结构。

\section{2 材料表征}

用差示扫描量热法(DSC, TA Q2000, 40 300 ${ }^{\circ} \mathrm{C}$, 升温速率 $10^{\circ} \mathrm{C} / \mathrm{min}, \mathrm{Al}_{2} \mathrm{O}_{3}$ 坩埚)和 $\mathrm{X}$ 射线衍射 (XRD, Philips $\chi^{\prime}$ Pert Pro)分析上述粉体的固化性能和产物 结构。用扫描电镜(SEM, FEI Quanta 200)和所配能 谱仪(EDS)分析样品表面形貌和成分。将样品包埋于 甲基丙烯酸甲酯中，打磨后观察涂层截面。柱状试 样 $(\phi 25 \mathrm{~mm} \times 50 \mathrm{~mm})$ 端面涂覆涂层后以 914 环氧树 脂 (天津燕海化学有限公司)粘接, 用材料试验机拉 伸至断裂(Instron 5567，1 mm/min)并计算涂层结合 强度 ${ }^{[16]}$ 。用动电位极化 $(\mathrm{CHI} 660 \mathrm{E}$, 上海辰华仪器有 限公司)评价样品的耐腐蚀性, 不锈钢样品为工作 电极, 铂片为辅助电极, 饱和甘录电极 (SCE) 为参比 电极, 扫描速度为 $4 \mathrm{mV} / \mathrm{s}$, 介质为 $3.5 \%(\mathrm{w} / \mathrm{w}) \mathrm{NaCl}$ 溶液。测试前用 400 目砂纸打磨 316-SS 对照样，其 余样品不进行打磨处理。用 Tafel 外推法确定腐蚀电 流密度 $\left(I_{\text {corr }}\right)$ 。

\section{3 涂层抗菌性能与机理}

将大肠杆菌(ATCC98082, 广东省微生物菌种 保藏中心)接种于牛肉亳蛋白胨琼脂培养基, $37^{\circ} \mathrm{C}$ 培 养 $24 \mathrm{~h}$ 后挑取单菌落转入液体培养基(均购自北京 奥博星生物技术有限公司)，培养 $24 \mathrm{~h}$ 后用磷酸盐 缓冲液(PBS)稀释至 $1 \times 10^{8} \mathrm{CFU} / \mathrm{mL}$ 。取 $40 \mu \mathrm{L}$ 菌悬 液涂于样品表面，室温培养 $2 、 12$ 和 $24 \mathrm{~h}$ 后用 $5 \mathrm{~mL}$ PBS 冲洗样品 ${ }^{[9]}$ 。取 $100 \mu \mathrm{L}$ 冲洗液逐级稀释后涂于 琼脂培养基表面，培养 $24 \mathrm{~h}$ 后根据形成的菌落数计 算样品表面存活的细菌数，进而计算其存活率(存 活率=样品表面存活的细菌数/样品表面初始接种的 细菌数), 每组各时间点 3 个平行样。

为了研究涂层的抗菌机理, 用含 $1 \mathrm{mmol} / \mathrm{L}$ 乙二胺 四乙酸(EDTA)的 PBS 将菌悬液稀释至 $1 \times 10^{8} \mathrm{CFU} / \mathrm{mL}$, 取 $40 \mu \mathrm{L}$ 涂布于样品表面 ${ }^{[6]}$, 培养 $24 \mathrm{~h}$ 后，同上测定 大肠杆菌存活率。 


\section{2 结果与讨论}

\section{1 固化过程与产物组成}

DSC 分析显示(图 1), 4 种涂层材料均从 $129^{\circ} \mathrm{C}$ 起始产生一个主吸热峰, 对应于固化反应, 并在 $\sim 210^{\circ} \mathrm{C}$ 出现一系列相对较弱的吸热峰。随着铜含量 增加, 主吸热峰逐渐变宽且峰顶温度略为升高(AlP: $148^{\circ} \mathrm{C}$, AlP- $0.025 \mathrm{Cu}: 149^{\circ} \mathrm{C}$, AlP- $0.05 \mathrm{Cu}: 151^{\circ} \mathrm{C}$, $\mathrm{AlP}-0.1 \mathrm{Cu}: 163^{\circ} \mathrm{C}$ )。DSC 曲线显示, 四种涂层材料的 缩合固化在 $<250^{\circ} \mathrm{C}$ 完成, 因此后续涂层制备采用 $250^{\circ} \mathrm{C}$ 固化。由于涂层较薄, 衍射信号较弱, 因此利 用涂层粉体表征固化产物结构。图 2 的 XRD 图谱显 示, 4 种粉体的固化产物中均存在 3 种主要晶相: $\mathrm{AlH}_{2} \mathrm{P}_{3} \mathrm{O}_{10} \cdot \mathrm{H}_{2} \mathrm{O}$ (三磷酸二氢铝)、 $\mathrm{AlPO}_{4}$ (柏林石) 和 $\mathrm{Al}_{8} \mathrm{H}_{12}\left(\mathrm{P}_{2} \mathrm{O}_{7}\right)_{9}$ (聚磷酸铝)。AlP- $0.05 \mathrm{Cu}$ 和 $\mathrm{AlP}-0.1 \mathrm{Cu}$ 的固化产物中出现 $\mathrm{Cu}_{2} \mathrm{P}_{2} \mathrm{O}_{7}$ (焦磷酸铜)的特征衍射峰, 且峰相对强度随铜含量同步增大, 表明涂层材料掺 入 $\mathrm{Cu}^{2+}$ 后固化产生了含铜的新相 $\mathrm{Cu}_{2} \mathrm{P}_{2} \mathrm{O}_{7}$ 。

各涂层溶液的热固化源于其中磷酸根离子与金 属离子形成连接相物质以及磷酸型体热缩合成为链 状结构 ${ }^{[12]}$ 。本实验所用磷酸铝的 $\mathrm{P}$ 与 $\mathrm{Al}$ 摩尔比为 2.3 ; $\mathrm{P}$ 与 $\mathrm{Al}$ 摩尔比 2.3 至 3 的磷酸铝具有良好的粘接性, 是重要的无机结合剂, 因此有许多研究表征该组成 范围内各种磷酸铝材料的热化学变化, 并均发现其 固化过程中的主要变化包括 ${ }^{[13,17]}:<100^{\circ} \mathrm{C}$, 磷酸铝溶 液干燥成为 $\mathrm{AlH}_{3}\left(\mathrm{PO}_{4}\right)_{2} \cdot \mathrm{H}_{2} \mathrm{O}$; 温度升至 $\sim 135^{\circ} \mathrm{C}$, $\mathrm{AlH}_{3}\left(\mathrm{PO}_{4}\right)_{2} \cdot \mathrm{H}_{2} \mathrm{O}$ 脱水并同时分解为等摩尔 $\mathrm{AlPO}_{4}$ 和 $\mathrm{Al}\left(\mathrm{H}_{2} \mathrm{PO}_{4}\right)_{3}$; 继续加热至 $215^{\circ} \mathrm{C}, \mathrm{Al}\left(\mathrm{H}_{2} \mathrm{PO}_{4}\right)_{3}$ 分解产生 $\mathrm{AlPO}_{4}$ 和 $\mathrm{AlH}_{2} \mathrm{P}_{3} \mathrm{O}_{10} \cdot \mathrm{H}_{2} \mathrm{O}$ 。这些变化与图 2 所显示的固 化过程主要吸热峰温度以及涂层中的主要相组成(图 2)基本一致。但由于实际采用的磷酸铝的组成与这些 主要反应的化学计量比并不完全一致, 因此固化过程 还可形成多种其他副产物, 如 $\mathrm{AlH}_{3}\left(\mathrm{PO}_{4}\right)_{2} \cdot \mathrm{H}_{2} \mathrm{O}$ 的形成 过程中溶液过量磷酸根可转化为游离磷酸,

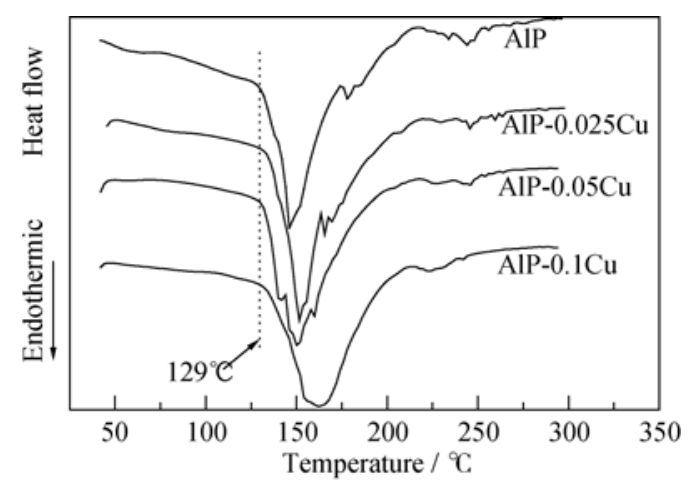

图 1 四种涂层材料的 DSC 曲线

Fig. 1 DSC curves of powders dried from coating solutions

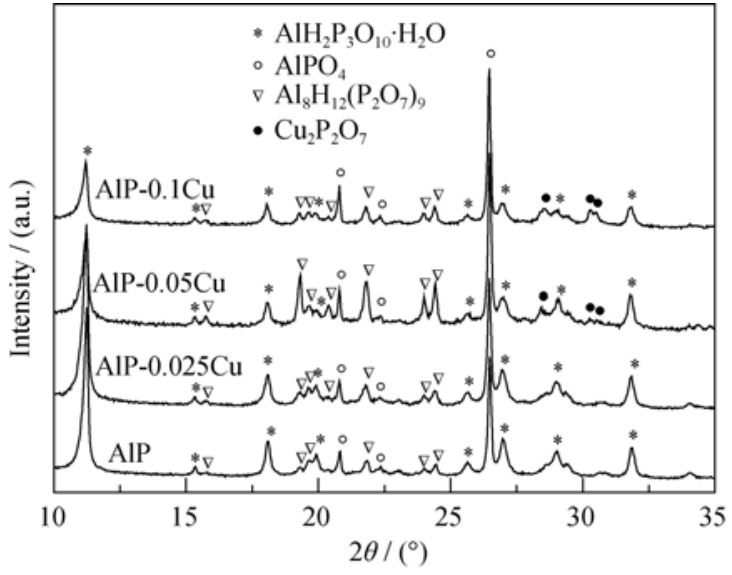

图 2 四种涂层材料固化产物的 XRD 图谱

Fig. 2 XRD patterns of powders dried from coating solutions after curing at $250^{\circ} \mathrm{C}$

并后续形成其他产物 ${ }^{[13]}$ 。此外, 研究发现磷酸铝固 化过程中可生成部分无定形物质, 该物质在 $250^{\circ} \mathrm{C}$ 部分结晶产生 $\mathrm{Al}_{8} \mathrm{H}_{12}\left(\mathrm{P}_{2} \mathrm{O}_{7}\right)_{9}{ }^{[18]}$, 这可以解释涂层中 $\mathrm{Al}_{8} \mathrm{H}_{12}\left(\mathrm{P}_{2} \mathrm{O}_{7}\right)_{9}$ 的形成过程。涂层中 $\mathrm{Cu}_{2} \mathrm{P}_{2} \mathrm{O}_{7}$ 由磷酸 根在 $200^{\circ} \mathrm{C}$ 以上热缩合并被 $\mathrm{Cu}^{2+}$ 连接形成，具体过 程则有待进一步研究。

\section{2 涂层形貌与成分}

经喷砂处理后的不锈钢(图 3(a))表面存在 $~ 5 \mu \mathrm{m}$ 的凹坑。各涂覆涂层的样品(图 3(b) (e))表面均较连 续平整，涂层完全覆盖基体，涂层无脱落或裂纹， 但存在直径约 1 3 $\mu \mathrm{m}$ 的孔洞，这可能与基体表面 粗糙或固化副产物(气态水)溢出有关。高倍率下观 察发现涂层内存在片状晶体(图 3(b) (e)中箭头), 晶 片由无特定形貌特征的区域连接形成连续涂层。随 着 $\mathrm{Cu}$ 含量增加, 晶片边界愈加清晰。

EDS 微区分析发现, 片状晶体(图 3(f), 区域 1)含 $22.2 \mathrm{at} \% \mathrm{P} 、 9.5 \mathrm{at} \% \mathrm{Al}$, 未检出 $\mathrm{Cu}$ ，与 $\mathrm{AlH}_{2} \mathrm{P}_{3} \mathrm{O}_{10} \cdot 2 \mathrm{H}_{2} \mathrm{O}$ 组成相对接近。片状晶体周边无形貌特征区域(区域 2)含 23.6at $\% \mathrm{P} 、 8.8 \mathrm{at} \% \mathrm{Al}$ 和 $0.6 \mathrm{at} \% \mathrm{Cu}$; 更高倍 $\mathrm{EDS}$ 成像未能发现 $\mathrm{Cu}$ 富集区域。因此，铜可能以更细小 颗粒的形式存在于该无形貌特征区域中，或以替换掺 杂形式存在于磷酸铝结构中, 其确切存在形式需进一 步研究。图 4 为两种涂层(316-AlP、316-AlP-0.05Cu) 的代表性截面照片，两种涂层厚度均为 $3 \mu \mathrm{m}$, 结构 致密，且与基体结合良好。

\section{3 抗菌性能与机理}

图 $5(\mathrm{a}, \mathrm{b})$ 分别显示大肠杆菌在样品表面培养 2 24 h 后的存活率和培养 $24 \mathrm{~h}$ 后所得冲洗液继续培 养 $24 \mathrm{~h}$ 后的菌落形成情况。接种 $2 \mathrm{~h}$ 后, 各样品表 面细菌存活率分别为 $(73.1 \pm 9.4) \%(316-\mathrm{SS}) 、(82.0 \pm$ $2.4) \%(316-\mathrm{AlP}) 、(71.2 \pm 1.4) \%$ (316-AlP-0.025Cu)、 $(75.9 \pm 5.1) \%$ (316-AlP-0.05Cu) 和 $(73.1 \pm 2.8) \%$ (316- 

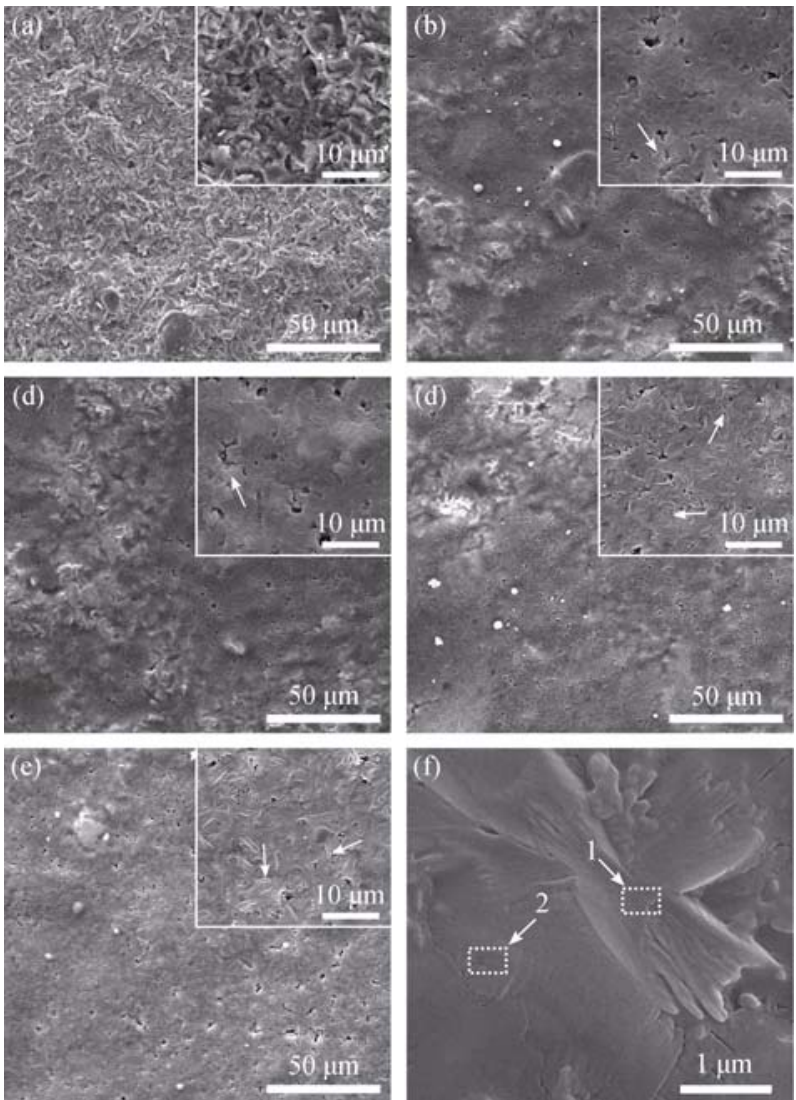

图 3 (a) 316-SS(喷砂后), (b) 316-AlP, (c) 316-AlP-0.025Cu, (d) 316-AlP-0.05Cu 和(e) 316-AlP-0.1Cu) 表面 SEM 照片; (f) EDS 微区分析区域

Fig. 3 SEM micrographs of (a) 316 stainless steel (gritblasted), (b) 316-AlP, (c) 316-AlP-0.025Cu, (d) 316-AlP$0.05 \mathrm{Cu}$, and (e) 316-AlP-0.1Cu; (f) regions of EDS microanalysis
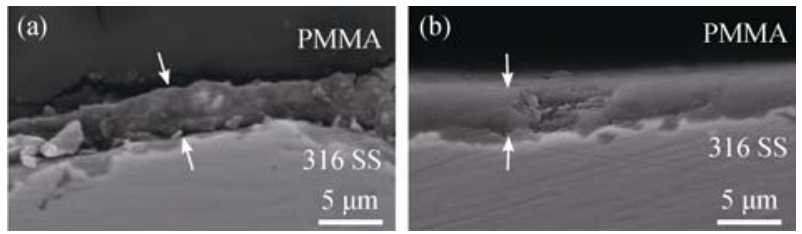

图 4 (a) 316-AlP 和(b) 316-AlP-0.05Cu 涂层截面的 SEM 照片

Fig. 4 Cross-section SEM images of (a) 316-AlP and (b) 316-AlP- $0.05 \mathrm{Cu}$ coatings (marked by arrows)

AlP-0.1Cu) (图 5(a))。此时所有样品细菌存活率均较 接种初期有所下降, 可能是由于细菌尚处于对新环 境(样品表面)的适应期 ${ }^{[19]}$, 增殖不活跃, 部分细菌 不适应新环境而死亡。接种 $12 \mathrm{~h}$ 后，316-SS 和 316-AlP 表面细菌存活率分别增至(75.5 13.1$) \%$ 和 (129.5 \pm 4.2$) \%$, 而 316-AlP-0.025Cu、316-AlP-0.05Cu 和 316-AlP-0.1Cu 的存活率分别降至 $(40.6 \pm 29.0) \%$ 、 $(27.8 \pm 23.5) \%$ 和 $(0.4 \pm 0.6) \%$ 。接种 $24 \mathrm{~h}$ 后, 316-SS 与

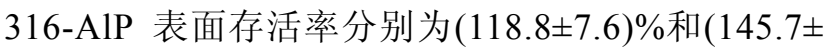
$18.8) \%$, 而各含铜涂层表面均未检出活菌(图 5(b))。
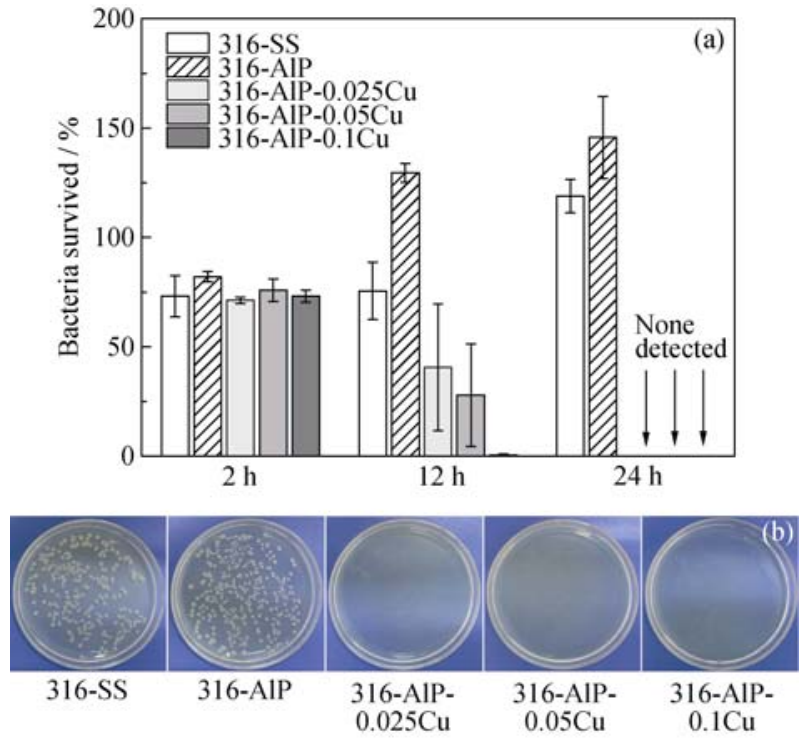

图 5 (a)大肠杆菌在不同表面的存活率及(b)细菌在样品表面 培养 $24 \mathrm{~h}$ 后冲洗液培养后的菌落形成情况

Fig. 5 (a) Survival rates of E.coli on various surfaces and (b) bacterial colonies formed by culture of dilutes

培养 12、24 h 后, 316-AlP 表面细菌存活率均高于 $316-S S$ ，可能与 AlP 涂层有关。Kuroda 等 ${ }^{[20]}$ 发现，在 贫营养条件下大肠杆菌可借助多聚磷酸根将菌体内 部自体蛋白质分解为氨基酸供给自身生存。但在本 研究最低铜掺杂量 $(\mathrm{Cu}: \mathrm{Al}=1: 40)$ 下即已消除涂层基体 的不利作用, 并在培养 $12 \mathrm{~h}$ 过程中产生杀菌能力。

大肠杆菌广泛分布于自然界, 是引起感染者腹 泻和肠炎的常见感染源之一, 致病型大肠杆菌甚至 可以造成死亡 ${ }^{[1]}$, 杀灭不锈钢表面大肠杆菌对减少 其感染具有实际意义。并且, 该方法制备的含铜涂 层对金黄色葡萄球菌也具有相似的杀菌性能。

目前已知含铜合金有两种杀菌机制：首先，合 金溶出的 $\mathrm{Cu}^{2+}$ 可以破坏细菌代谢途径，引起菌体死 亡; 其次, 菌体-金属表面直接接触也可导致细菌死 亡。某些细菌在不直接接触铜金属表面情况下生存 率可显著上升。Mathews 等 ${ }^{[21]}$ 用微孔膜将海氏肠球 菌(E. hirae)与铜合金表面分隔，发现与二者直接接 触相比, 细菌的杀灭率下降了 7 个数量级。为确认 含铜涂层的杀菌机理, 向菌悬液加入 $1 \mathrm{mmol} / \mathrm{L}$ EDTA 后比较细菌在涂层表面的生存率 ${ }^{[6]}$ 。EDTA 可 与 $\mathrm{Cu}^{2+}$ 形成稳定的配合物而降低菌悬液中的游离 $\mathrm{Cu}^{2+}$ 浓度, 因此可检验杀菌能力是否源于表面溶出 的 $\mathrm{Cu}^{2+}$ 。含EDTA 的菌悬液接种并培养 $24 \mathrm{~h}$ 后(图6), 细 菌在各涂层表面均呈增殖趋势，316-AIP- $0.025 \mathrm{Cu}$ 、 316-AlP- $0.05 \mathrm{Cu}$ 和 316-AlP-0.1Cu 表面存活率分别 为 $(221.3 \pm 15.5) \% 、(251.8 \pm 6.8) \%$ 和 $(218.6 \pm 17.1) \%$, 表 明其抗菌性源于表面溶出的 $\mathrm{Cu}^{2+}$ 。 


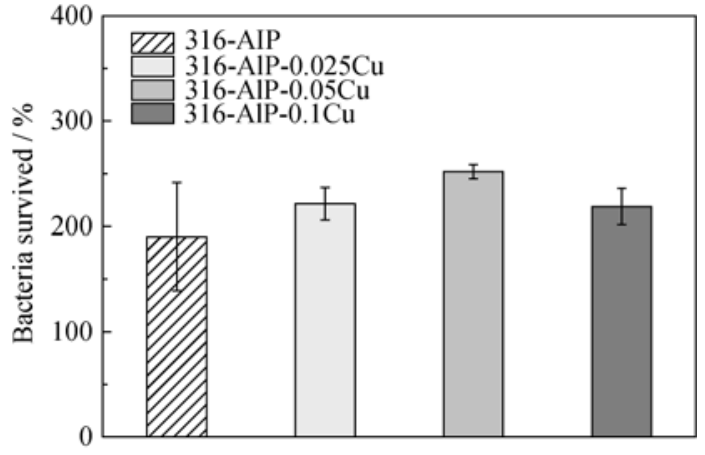

图 6 加入 EDTA 对涂层表面大肠杆菌生存率的影响

Fig. 6 Effect of EDTA addition to culture medium on survival rates of E.coli on various surfaces

\section{4 结合强度与耐腐蚀性}

拉伸试验显示各涂层结合强度分别为(17.2 \pm 3.9$)$ MPa (316-AlP)、(16.3 \pm 3.4$) \mathrm{MPa}(316-\mathrm{AlP}-0.025 \mathrm{Cu})$ 、 $(18.1 \pm 2.2) \mathrm{MPa}(316-\mathrm{AlP}-0.05 \mathrm{Cu})$ 和 $(14.5 \pm 2.7) \mathrm{MPa}$ (316-AlP-0.1Cu), 表明各涂层与基体结合良好。除机 械嵌合外, 磷酸铝涂层与不锈钢表面还存在化学作 用 ${ }^{[7]}$ 。由于 $\mathrm{P}-\mathrm{OH}$ 基团具有中等酸性, 可与金属氧化 物(如 $\mathrm{Al}_{2} \mathrm{O}_{3} 、 \mathrm{SiO}_{2}$ ) 的表面羟基发生化学吸附, 因此 磷酸铝与多种材料具有良好的粘接能力。

极化曲线(图 7)显示, 涂覆涂层样品的极化电 流相对于无涂层样品均显著降低。Tafel 外推表明, $316-\mathrm{SS}$ 的腐蚀电流密度 $\left(I_{\mathrm{corr}}\right)$ 为 $2.8 \times 10^{-6} \mathrm{~A} / \mathrm{cm}^{2}$; 316-AlP、316-AlP-0.025Cu、316-AlP-0.05Cu 和 316$\mathrm{AlP}-0.1 \mathrm{Cu}$ 的 $I_{\text {corr }}$ 分别为 $8.1 \times 10^{-8} 、 3.6 \times 10^{-8} 、 6.6$ $\times 10^{-8}$ 和 $7.3 \times 10^{-8} \mathrm{~A} / \mathrm{cm}^{2}$, 仅为 $316-\mathrm{SS}$ 的 $2.9 \%$ 、 $1.3 \% 、 2.4 \%$ 和 $2.6 \%$, 表明各涂层将不锈钢基体的腐 蚀速率降低了近 2 个数量级。通过体相引入铜元素 制备的抗菌不锈钢中由于存在富铜的合金相, 易形 成微电池而导致耐腐蚀性劣化。而磷酸铝涂层结构 致密(图 4), 可阻挡腐蚀介质渗入, 其中铜元素不以

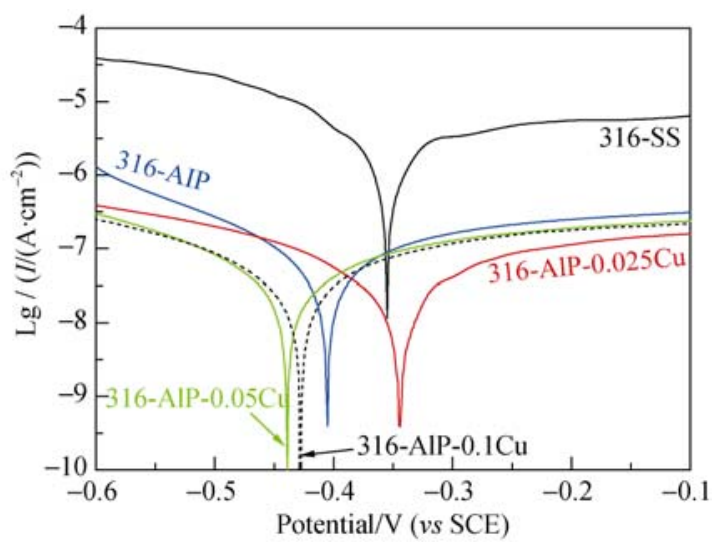

图 7 样品的动电位极化曲线

Fig. 7 Potentiodynamic polarization curves of samples
金属相形式存在，避免形成微电池，因此显著降低 了不锈钢的腐蚀速率。

实验制备的含铜涂层可赋予不锈钢抗菌性且不 造成耐腐蚀性劣化，具有应用价值。但与合金化和 表面注入等方法制备的抗菌不锈钢相比 ${ }^{[6-8]}$, 该涂 层杀菌速度较慢, 这可能与其铜含量较低有关。实 验发现，进一步提高涂层溶液中 $\mathrm{Cu}^{2+}$ 浓度会引起溶 液逐渐沉淀, 因此需要探索其他方式提高涂层原料 中铜含量而不影响操作性。研究发现, 磷酸氢铝与 $\mathrm{ZnO} 、 \mathrm{CaO} \cdot \mathrm{Al}_{2} \mathrm{O}_{3} 、 \mathrm{CuO}$ 等氧化物粉体复合后, 这些 粉体可释放金属离子与磷酸结构交联, 并实现(近) 室温固化 ${ }^{[13,22]}$ 。因此, 进一步工作将研究复合 $\mathrm{CuO}$ 等粉体组份, 提高涂层中抗菌元素含量, 近室温下 制备具有更快速抗菌性能的无机涂层。

\section{3 结论}

利用磷酸二氢铝的热固化在不锈钢表面制备了 不同铜含量的磷酸铝涂层。涂层可于 $\leqslant 250^{\circ} \mathrm{C}$ 下固化; 掺入 $\mathrm{Cu}^{2+}$ 后, 固化产物中形成含铜新相 $\mathrm{Cu}_{2} \mathrm{P}_{2} \mathrm{O}_{7}$ 。 与大肠杆菌接触 $12 \mathrm{~h}$ 后, 各含铜涂层均可有效抑制 表面细菌的存活, 且抑菌能力与涂层铜含量呈正相 关。接触 $24 \mathrm{~h}$ 后, 各含铜涂层均完全杀死表面细菌。 涂层的抗菌性来自于 $\mathrm{Cu}^{2+}$ 释放。涂层也有助于降低 不锈钢的腐蚀速率。本研究显示, 利用磷酸铝可制 备含铜等抗菌元素的无机涂层。该技术制备温度较 低，对铜利用率高且不造成金属基底性能劣化，有 一定应用前景。研究也显示, 利用无机聚合物是制 备抗菌涂层的一种可行途径。

\section{参考文献:}

[1] KASSEM I I. Chinks in the armor: The role of the nonclinical environment in the transmission of Staphylococcus bacteria. American Journal of Infection Control, 2011, 39(7): 539-541.

[2] CHERNOUSOVA S, MATTHIAS E. Silver as antibacterial agent: ion, nanoparticle, and metal. Angewandte Chemie International Edition, 2013, 52(6): 1636-1653.

[3] HE H, WANG J, GO Q, et al. Ag-silica composite nanotubes with controlled wall structures for biomedical applications. Colloids and Surfaces B: Biointerfaces, 2013, 111: 693-698.

[4] GRASS G, RENSING C, SOLIOZ M. Metallic copper as an antimicrobial surface. Applied and Environmental Micribiology, 2011, 77(5): 1541-1547.

[5] WU Q, LI J, ZHANG W, et al. Antibacterial property, angiogenic and osteogenic activity of $\mathrm{Cu}$-incorporated $\mathrm{TiO}_{2}$ coating. Journal of Materials Chemistry B, 2014, 39(2): 6738-6748. 
[6] NAN L, YANG W, LIU Y, et al. Antibacterial mechanism of copper-bearing antibacterial stainless steel against $E$. Coli. Journal of Materials Science and Technology, 2008, 24(2): 197-201.

[7] ZHANG X Y, JIANG L, HUANG X B, et al. Improvement of antibacterial properties of stainless steel by combining plasma $\mathrm{Cu}$ and thermal diffusion. Journal of Inorganic Materials, 2012, 27(5): $519-523$.

[8] DAN Z, NI H, XU B, et al. Microstructure and antibacterial properties of AISI 420 stainless steel implanted by copper ions. Thin Solid Films, 2005, 492(1): 93-100.

[9] TRAPALIS C C, KOKKORIS M, PERDIKAKIS G, et al. Study of antibacterial composite $\mathrm{Cu} / \mathrm{SiO}_{2}$ thin coatings. Journal of Sol-Gel Science and Technology, 2003, 26(1/2/3): 1213-1218.

[10] VASCONCELOS D C L, CARVALHO J A N, MANTEL M, et al. Corrosion resistance of stainless steel coated with Sol-Gel silica, Journal of Non-Crystalline Solids, 2000, 271(1): 135-139.

[11] JAIN S, BUDIANSKY N D, HUDSON J L, et al. Surface spreading of intergranular corrosion on stainless steels. Corrosion Science, 2010, 52(3): 873-885.

[12] HAN H, KIM D. Studies on curing chemistry of aluminum-chromium-phosphates as low temperature curable binders. Journal of Sol-Gel Science and Technology, 2003, 26(1/2/3): 223-228.

[13] HE L, CHEN D, SHANG S. Fabrication and wear properties of $\mathrm{Al}_{2} \mathrm{O}_{3}-\mathrm{SiC}$ ceramic coatings using aluminum phosphate as binder. Journal of Materials Science, 2004, 39(15): 4887-4892.

[14] HAWTHORNE H M, NEVILLE A, TROCZYNSKI T, et al. Characterization of chemically bonded composite-Sol-Gel based alumina coatings on steel substrates. Surface and Coatings Technology. 2004, 176(2): 243-252.

[15] MUNOZ T, PRAKASH A M, KEVAN L, et al. Synthesis and characterization of CuAPO-5 molecular sieves: evidence for the framework incorporation of $\mathrm{Cu}$ (II) ions. Journal of Physical Chemistry, 1998, 102(8): 1379-1386.

[16] LIUD M, YANG Q, TROCZYNSKI T. Sol-Gel hydroxyapatite coatings on stainless steel substrates. Biomaterials, 2002, 23(3): 691-698.

[17] MORRIS J H, PERKINS P G, ROSE A E A, et al. The chemistry and binding properties of aluminium phosphates. Chemical Society Reviews, 1977, 6(2): 173-194.

[18] GILMORE R. Phosphoric Acid, Purification, Uses, Technology, and Economics. Boca Raton: CRC Press, 2014: 280.

[19] 周长林. 微生物学与基础免疫学, 2 版. 南京: 东南大学出版社, 2008: 123.

[20] KURODA A, NOMURA K, OHTOMO R, et al. Role of inorganic polyphosphate in promoting ribosomal protein degradation by the Lon protease in E. coli. Science, 2001, 293(5530): 705-708.

[21] MATHEWS S, HANS M, MUCKLICH F, et al. Contact killing of bacteria on copper is suppressed if bacteria-metal contact is prevented and is induced on iron by copper ions. Applied and Environmental Microbiology, 2013, 79(8): 2605-2611.

[22] CHEN Z, ZHANG L, ZHOU K C. Research progress of phosphate inorganic binder for high temperature resistance. Materials Science and Engineering of Powder Metallurgy, 2009, 2(14): 74-82. 